\title{
Root causes for late presentation of severe neonatal hyperbilirubinaemia in Egypt
}

\author{
I. Iskander, ${ }^{1}$ R. Gamaleldin ${ }^{1}$ and M. Kabbani ${ }^{2}$
}

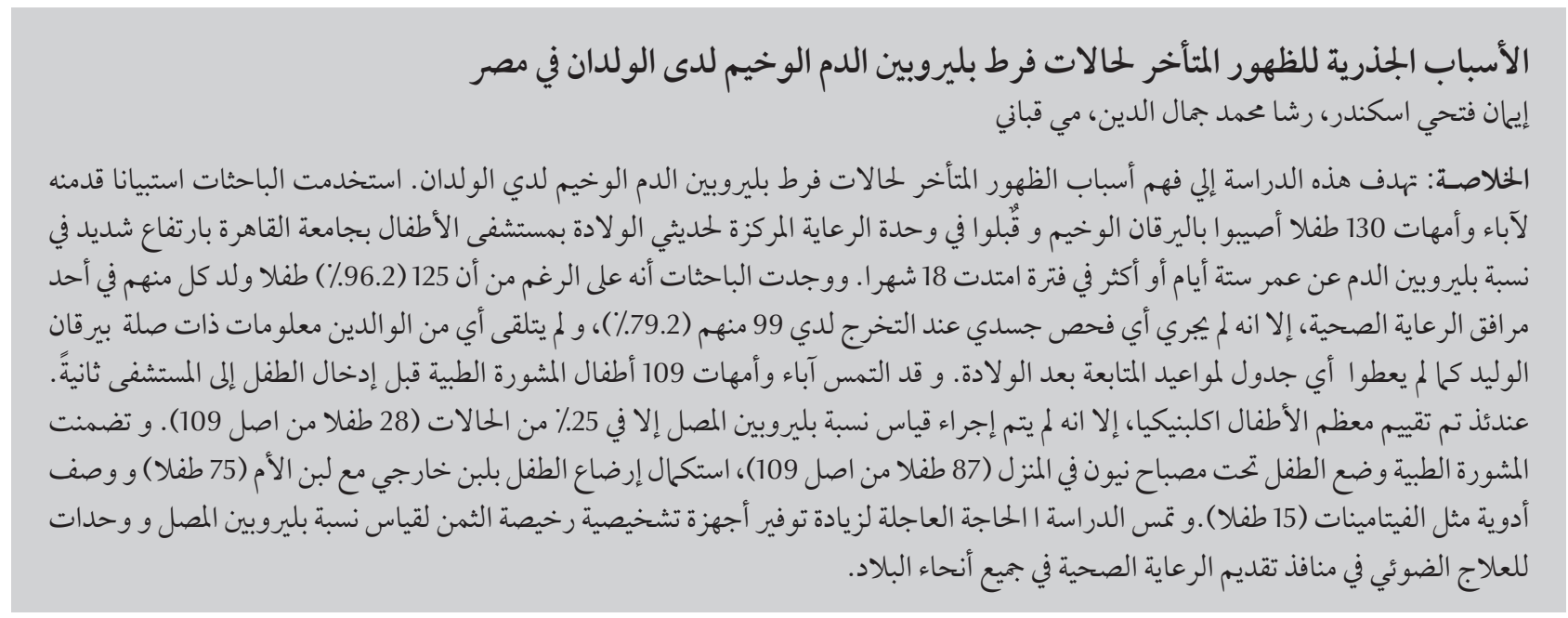

ABSTRACT This study aimed to understand the reasons for late presentation of cases of severe neonatal hyperbilirubinaemia. We administered a questionnaire to parents of 130 infants with severe jaundice admitted to Cairo University Children's Hospital neonatal intensive care unit at age $\geq 6$ days over an 18-month period. Although 125 infants (96.2\%) were delivered in a health care facility, no discharge physical examination was performed in 99/125 cases (79.2\%). No parent was given instructions about neonatal jaundice and no follow-up appointments were scheduled. Parents of 109 infants sought medical advice prior to hospital readmission; most babies were assessed clinically, but serum bilirubin was measured in only one-quarter of cases (28/109). Medical advice included placing the infant under a neon lamp at home (87/109 cases), advice to supplement breastfeeding (75/109) and prescribed medications, including vitamins (15/109). Increasing the availability of inexpensive pointof-care diagnostic instruments and phototherapy units in health care facilities are urgently needed.

Causes profondes de la présentation tardive des enfants atteints d'une hyperbilirubinémie néonatale sévère en Égypte

RÉSUMÉ La présente étude visait à établir les raisons de la présentation tardive des enfants atteints d'une hyperbilirubinémie néonatale sévère. Nous avons administré sur une période de 18 mois, un questionnaire aux parents de 130 enfants atteints d'un ictère sévère et admis à l'âge de 6 jours ou plus dans l'unité néonatale des soins intensifs du centre hospitalier universitaire pour enfants du Caire. Même si 125 enfants (96,2 \%) étaient nés dans un établissement de soins, aucun examen médical de sortie n'avait été réalisé dans 99 cas sur 125 (79,2\%). Aucun parent n'avait reçu d'instructions concernant l'ictère néonatal et aucune consultation de suivi n'avait été programmée. Les parents de 109 enfants avaient consulté un médecin avant la réadmission de leur enfant à l'hôpital ; toutefois, si la majorité des enfants avaient bénéficié d'un examen clinique, leur taux de bilirubine sérique n'avait été analysé que dans un quart des cas (28 sur 109). Les conseils médicaux prodigués consistaient à placer l'enfant sous une lampe au néon à son domicile (87 cas sur 109), à donner des compléments alimentaires en plus du lait maternel (75 cas sur 109) et à administrer des médicaments, notamment des vitamines (15 cas sur 109). Accroître la disponibilité des instruments diagnostiques d'un faible coût au chevet du patient et des unités photothérapeutiques dans les établissements de soins représente une urgente nécessité. 


\section{Introduction}

Neonatal jaundice is generally considered a benign self-limiting condition, affecting more than $60 \%$ of healthy term and late preterm infants $[1,2]$. However, severe neonatal hyperbilirubinaemia can lead to irreversible brain damage and kernicterus [3]. Perhaps due to a greater awareness of its risks and the concerted efforts from professional societies [46], the reported incidence of hazardous hyperbilirubinaemia (bilirubin level > $510 \mathrm{mmol} / \mathrm{L}$ ) is very low. Surveys show an incidence of 7.1/100 000 in the UK and Ireland over a period of 2 years [7] with $0.9 / 100000$ incidence of acute bilirubin encephalopathy [8], while in the USA the reported incidence of hazardous hyperbilirubinaemia is $1 / 10000$ and reported incidence of kernicterus is $1.5 / 100000[9,10]$.

A different picture is seen in resourcelimited countries [11]. Acute bilirubin encephalopathy remains a common clinical finding in Nigeria with an incidence of between $2.5 \%-3.4 \%$ of hospital admissions in the neonatal period [12]. In Cairo University Children's Hospital, severe neonatal hyperbilirubinaemia accounted for $33 \%$ of total admission diagnoses to the outborn neonatal intensive care unit (NICU) in 2006 [13] with about 10 cases of kernicterus occurring each year [14]. The interesting finding in the previous study was that almost half of those infants were admitted after the fifth day of life, often with signs of acute bilirubin encephalopathy [13]. Although the contribution of delayed recognition and management of cases with severe neonatal hyperbilirubinaemia is well known to increase the risk of acute bilirubin encephalopathy and later kernicterus, no previous study has examined the underlying factors that lead to late presentation of those cases in our community, Therefore, the aim of this study was to prospectively evaluate the social, cultural, educational and systems-related factors contributing to the late presentation of infants with severe neonatal hyperbilirubinaemia to a public (free-of-charge) hospital in Egypt.

\section{Methods}

\section{Study design and sample}

Newborns, 6 days of age or older, admitted to the outborn NICU of Cairo University Children's Hospital in Cairo, Egypt, with the sole diagnosis of severe neonatal hyperbilirubinaemia were eligible for the study. Infants with jaundice who had any other medical or surgical conditions that required intervention at admission were excluded from the study. The hospital is a publicly funded, free-of-charge 500 bed tertiary care hospital that mainly serves as a referral centre for infants and children requiring sophisticated medical care and who cannot afford private health care facilities.

A detailed clinical history including family history of haemolytic disorders was obtained for each case. A standard laboratory work-up was carried out to assess the medical causes for jaundice, including: serum bilirubin, complete blood count, reticulocyte count, blood group of mother and infant, Coombs test and others as indicated. All infants were managed according to the unit protocol, which follows the recommendations of the American Academy of Pediatrics (AAP) for the management of severe neonatal jaundice [5].

In addition, we administered a survey questionnaire to parents to explore reasons for delayed admission of babies with severe neonatal hyperbilirubinaemia. All parents of infants fulfilling the criteria for admission to the NICU from November 2006 to April 2008 and consenting to participate in the study were interviewed. The study and the questionnaire form were approved by the Cairo University institutional review board

\section{Data collection}

The interviewer (professor of paediatrics) initially informed the parents about the aim of the study and requested the parents' consent. Consenting parents were then interviewed. The questionnaire included 60 questions that addressed various aspects of neonatal hyperbilirubinaemia and its management. Most questions were designed using a "yes/no" answer format, with a possibility to provide single or multiplechoice replies. Open-ended questions were minimized as much as possible. The questionnaire was pre-tested for clarity.

The questionnaire gathered demographic data, birthing data and postnatal information prior to admission. Parents were asked about delivery and postnatal history in birthing centres, details of infant examinations, instructions given regarding feeding, bowel movements, and jaundice, the infant's age at discharge and follow-up appointments. Questions also focused on the steps taken by parents once they noticed their infant's jaundice, including feeding practices, the time intervals between noticing jaundice and seeking medical advice, the parents' attitude and knowledge about neonatal jaundice, advice given to them by friends and family and the diagnostic and treatment instructions given by any physician(s) prior to their referral to our hospital.

\section{Statistical analysis}

The statistical analyses consisted of calculating descriptive statistics [mean, standard deviation (SD) and range] using Statistica, version 6.0 for Windows (StatSoft Inc.).

\section{Results}

From November 2006 to April 2008, a total of 1006 infants were admitted to the outborn NICU; 482 were admitted with a sole diagnosis of neonatal jaundice, of whom 195 met the inclusion criteria ( $\geq 6$ days old). The parents of 130 infants meeting the eligibility criteria consented to answer the questionnaire and were included in this 
report. The main reason for refusal to participate in the study was because the parent bringing the baby was stressed or could not afford the time required to sit down and talk for almost an hour. The demographic data of the studied infants are shown in Table 1.

Almost all of the 130 infants (125, 96.2\%) were delivered at a health care facility, such as a local maternity hospital or private birthing clinic, and 5 were born at home. Of these 125 mother-infant dyads 99 (79.2\%) were discharged from the birthing facility within 24 hours of delivery. In $79 / 125$ of cases (63.2\%), the parents reported that no clinical examination was carried out on the baby prior to discharge. Serum bilirubin was measured in only 3 infants before discharge from maternity hospital after mothers had reported previous babies with severe jaundice and had asked for a check-up. None of the parents of these 125 infants received any specific instructions concerning jaundice and no follow-up appointments or plans were established.

In most cases, neonatal jaundice was first noticed by the parents or a close relative. Almost 50\% of parents did not quickly seek medical advice due to the belief that jaundice is a normal finding in newborns that would resolve with time.

Prior to arrival at Cairo University Children's Hospital, parents of 109 infants had already sought medical advice at local clinics, yet serum bilirubin measurements were ordered in only 28 of these cases $(25.7 \%)$. At these local clinics, 87 of these parents (79.8\%) were advised by doctors to "place the infant under neon light” at home, 75 were advised to supplement breastfeeding with herbal infusions or formula milk to promote stooling and correct any dehydration and 15 infants were prescribed a variety of medications, including vitamins. In 22 cases doctors advised that the infant be taken to hospital immediately; despite that, parents of 9 of these infants took no action until the babies started to become lethargic. At the time of arrival at the hospital,

\begin{tabular}{|c|c|c|}
\hline Variable & No. & $\%$ \\
\hline \multicolumn{3}{|l|}{ Residence } \\
\hline Urban & 47 & 36.2 \\
\hline Rural & 83 & 63.8 \\
\hline \multicolumn{3}{|l|}{ Education } \\
\hline Literate & 98 & 75.4 \\
\hline Illiterate & 32 & 24.6 \\
\hline \multicolumn{3}{|l|}{ Gravidity } \\
\hline Primipara & 88 & 67.7 \\
\hline Multipara & 42 & 32.3 \\
\hline \multicolumn{3}{|l|}{ Employment } \\
\hline Working & 55 & 42.3 \\
\hline Non-working & 75 & 57.7 \\
\hline \multicolumn{3}{|c|}{ Parental consanguinity ${ }^{a}$} \\
\hline Positive & 24 & 18.5 \\
\hline \multicolumn{3}{|l|}{ Sex } \\
\hline Male & 89 & 68.5 \\
\hline Female & 41 & 31.5 \\
\hline \multicolumn{3}{|l|}{ Delivery } \\
\hline Hospital & 96 & 73.8 \\
\hline Private clinic & 29 & 22.3 \\
\hline Home & 5 & 3.8 \\
\hline \multicolumn{3}{|l|}{ Mode of delivery } \\
\hline Vaginal & 94 & 72.3 \\
\hline Cesarean section & 36 & 27.7 \\
\hline \multicolumn{3}{|c|}{ Discharge from maternity (hours) ${ }^{b}$} \\
\hline$\leq 24$ & 99 & 79.2 \\
\hline $25-48$ & 18 & 14.4 \\
\hline$>48$ & 8 & 6.4 \\
\hline \multicolumn{3}{|l|}{ Feeding } \\
\hline Breast & 87 & 66.9 \\
\hline Formula & 11 & 8.5 \\
\hline Both & 6 & 4.6 \\
\hline Breast + others $^{c}$ & 26 & 20.0 \\
\hline
\end{tabular}

${ }^{a}$ First counsins, ${ }^{b} n=125$ deliveries in health care facilities; ${ }^{c}$ glucose or herbal infusions.

parents of 41 infants had already gone to 2 or 3 hospitals in search of available or affordable phototherapy before finding a place at our facility, with some travelling for more than 5 hours.

\section{Clinical course}

The clinical variables and the severity of hyperbilirubinaemia at the time of admission are shown in Tables 2 and 3 respectively. The magnitude of the problem is demonstrated clearly in Table 3, which shows that although the reported incidence of hazardous hyperbilirubinaemia (i.e. bilirubin levels $>513 \mathrm{mmol} / \mathrm{L}$ ) was 1:10 000, in our study 19/130 cases had hazardous hyperbilirubinaemia (14.6\%). While the reported onset of the infant's jaundice was observed at a mean age of 4.1 days of life, the mean age of presentation at the hospital was 9.4 days (Table 2). 


\begin{tabular}{|c|c|c|}
\hline \multicolumn{3}{|c|}{$\begin{array}{l}\text { Table } 2 \text { Admission data of the study newborns admitted with neonatal jaundice } \\
(n=130)\end{array}$} \\
\hline Variable & Range & Mean (SD) \\
\hline Day of admission after birth & $6-24$ & $9.4(2.9)$ \\
\hline Observed onset of jaundice (days) & $2-9$ & $4.1(3.4)$ \\
\hline Weight on admission (kg) & $1.78-4.32$ & $2.80(0.73)$ \\
\hline Gestational age on admission (weeks) & $35-41$ & $38.2(1.4)$ \\
\hline Bilirubin level on admission ( $\mu \mathrm{mol} / \mathrm{L})$ & $308-811$ & $440(75)$ \\
\hline
\end{tabular}

$S D=$ standard deviation .

Table 4 shows the suspected etiologies for the jaundice. The most common cause of severe neonatal jaundice among the studied infants was $\mathrm{ABO}$ incompatibility. Although Rhesus incompatibility should be completely preventable (since the introduction of anti-D antibody), it still accounted for $8.5 \%$ of cases. The cause of severe neonatal hyperbilirubinaemia was unidentified in $40.0 \%$ of the studied infants. All infants in the study were placed under intensive phototherapy as recommended by the AAP [5]. An exchange transfusion was carried out in 71 infants; 14 required a second exchange transfusion.

Of the 130 infants, 14 had signs of acute bilirubin encephalopathy at the time of hospital admission. Of these, 3 died and 11 were discharged home. The cause of death in 2 infants was severe bilirubin encephalopathy complicated by fulminate sepsis and the third newborn was admitted with severe bilirubin encephalopathy and developed apnoea and arrest within 24 hours of admission following exchange transfusion. Among the 11 infants discharged, 7 appeared to have recovered from the signs of acute brain encephalopathy, whereas 4 were discharged with persistent neurological signs for follow-up.

\section{Discussion}

In this first systematic study in Egypt of a cohort of infants with severe neonatal hyperbilirubinaemia, we attempted to explore systems-related factors that might have contributed to the late presentation of cases with severe neonatal hyperbilirubinaemia in our patient population, a problem which increases the risk of preventable neonatal brain injury (kernicterus). While we do not have an appropriate denominator to estimate the incidence of severe neonatal hyperbilirubinaemia and kernicterus in Egypt, the high admission rate in a single tertiary care (free-of-charge) hospital reflects a high prevalence of the illness among socially deprived children whose families cannot afford private medical care. Since bilirubin-induced brain injury and kernicterus still occur fairly commonly in the Middle East and other resource-limited countries in the world $[12,14]$, our findings provide some insight into social and medical behaviours that contribute to this tragic, preventable, complication of neonatal jaundice.

Although it is reassuring that $96.2 \%$ of the infants in this study were born at a health care facility, it is a matter of great concern that $79.2 \%$ infants were discharged within 24 hours of age with little or no evaluation for the risk of developing jaundice or any instructions for follow-up. Clinical or laboratory assessment of jaundice was almost nonexistent even among those who were discharged after day 2 of age.

There is a worldwide tendency nowadays to shorten hospital stays and promote early discharge from maternity hospitals to reduce the cost of care. One of the major problems associated with early discharge of the mother and her newborn from maternity hospitals is neonatal hyperbilirubinaemia (which is also the most frequent reason for hospital readmissions) $[15,16]$. The lack of awareness among health care workers in maternity settings about bilirubin biology and its potential for neurotoxicity and the absence of set protocols for predischarge examination and followup instructions regarding jaundice in low-income health care facilities in our country are similar to problems prompting revision of the AAP guidelines in the United States in 2004 [7].

Neonatal jaundice, a very common and mostly benign condition, is viewed with a false sense of security regarding its potential consequences by both physicians and parents. Parents tend to seek medical advice only when more ominous signs such as lethargy or poor feeding occur. Although jaundice was observed at a mean age of 4.1 days of life

\begin{tabular}{|c|c|c|c|c|}
\hline Level of jaundice ( $\mu \mathrm{mol} / \mathrm{L})$ & Proposed definition & Estimated occurrence $^{a}$ & No. of cases & $\%$ of total cases \\
\hline$\geq 290$ & Significant & 1:10 & 6 & 4.6 \\
\hline$\geq 340$ & Severe & $1: 70$ & 48 & 36.9 \\
\hline$\geq 427$ & Extreme & $1: 700$ & 57 & 43.8 \\
\hline$\geq 513$ & Hazardous & 1:10 000 & 19 & 14.6 \\
\hline
\end{tabular}

${ }^{a}$ United States population [4]. 


$\begin{aligned} & \text { Table 4 Suspected causes of hyperbilirubinaemia among the studied newborns } \\
& \text { admitted with neonatal jaundice }(\boldsymbol{n}=\mathbf{1 3 0})\end{aligned}$
\begin{tabular}{lcc} 
Cause & No. of cases & $\%$ \\
Undetermined & 52 & 40.0 \\
ABO incompatibility & 33 & 25.4 \\
Dehydration & 18 & 13.8 \\
Sepsis & 12 & 9.2 \\
Rhesus incompatibility & 11 & 8.5 \\
Bruising & 10 & 7.7 \\
Other haemolytic disorders & 7 & 5.4 \\
Polycythaemia & 6 & 4.6 \\
Breastmilk & 2 & 1.5 \\
\hline
\end{tabular}

in this study, there was a significant delay in presentation to the hospital which occurred at a mean age of 9.4 days.

The delay in seeking treatment was further compounded by faulty medical advice. Our study demonstrated very low utilization of laboratory services for serum bilirubin measurement and hence excessive reliance on clinical ability to visually assess jaundice severity using the cephalocaudal progression. This approach can be fraught with serious inaccuracies especially in infants with pigmented skin $[5,17,18]$. In the current study, serum bilirubin measurement was ordered for only one-quarter of newborns clinically examined for jaundice. Presumably in others, the medical practitioner decided that the jaundice was not severe enough. Although transcutaneous bilirubinometry is a reliable, easy-to-use, screening tool for follow-up of neonatal jaundice without blood withdrawal $[19,20]$, its use in Egypt is quite restricted because it is not available to most Egyptian paediatricians outside the capital and is relatively costly to use.

Before admission a wide range of treatments were utilized in our cohort, most of which led to additional delay in implementing proper treatment of severe neonatal hyperbilirubinaemia. Placing babies under neon lamps at home, a very ineffective form of phototherapy, was suggested by many medical practitioners. Furthermore, prescription of vitamins for neonatal jaundice was not only useless but may also have given parents false reassurance that their jaundiced infant was being treated. Lack of availability of affordable phototherapy units in public hospitals in Egypt, especially in remote areas in the country, further augments the problem. In this study, 41 parents had to go to more than 1 hospital in search for phototherapy before admission. Some had to travel for more than 5 hours.

This study identified many key factors leading to the late presentation of cases with severe neonatal hyperbilirubinaemia, which can precipitate the occurrence of bilirubin encephalopathy and eventually kernicterus, thus providing a framework to construct solutions. There is an urgent need to develop comprehensive educational and training programmes for health care workers throughout the country regarding the neurotoxic potential of bilirubin, the exposure-time factor and how to avoid it. The value of screening infants for jaundice before hospital discharge and using the hour-specific nomogram for accurate risk assessment and timely follow-up scheduling cannot be overemphasized. An outreach programme for examining and screening infants discharged on day 1 or born at home is essential, especially for people living in remote areas. Parents need to be educated about jaundice and the risk of kernicterus, and the importance of complying with proper follow-up appointments to prevent its occurrence. These efforts may need to be combined with media campaigns to raise community and physician awareness about risks of severe neonatal hyperbilirubinaemia.

In Egypt, increasing the availability of inexpensive point-of-care diagnostic instruments and phototherapy units in health care facilities throughout the country and training personnel to use them are urgently needed. Incorporating universal bilirubin screening along with the existing mandated thyroid screening programme at 3-6 days of age would provide important epidemiological data and identify babies with or at-risk of developing severe neonatal hyperbilirubinaemia who would otherwise be missed.

Delayed presentation of severe neonatal hyperbilirubinaemia is one of the main root causes that can result in kernicterus. Issues identified in this study are not exclusive to Egypt but are strikingly similar to those identified in some areas of the United States a few years ago [21]. A study by Atkinson et al. showed wide interhospital variation and poor adherence among paediatricians to AAP guidelines for the management of severe neonatal hyperbilirubinaemia [22]. These findings show that the problem of severe neonatal hyperbilirubinaemia and its solutions transcends social differences and economic maturity of various health care systems all over the world. While tactics to prevent and treat severe neonatal hyperbilirubinaemia must be sensitive to cultural and resource variations, the universality of root causes suggests that a common strategy may be applied to make kernicterus, (the preventable handicap), a very rare event throughout the world.

This study was not without limitations. It relied primarily on parental recall which might be affected by issues related to parental perception and the 
known inaccuracies of recall. Another possible limitation might be related to the number of parents who refused to participate, yet we believe that it is unlikely to have biased the results of this study.

\section{Acknowledgements}

We thank Richard P. Wennberg, Clinical Professor of Pediatrics and Neonatology, University of Washington, Tonse N.K. Raju, Program Officer, Eunice
Kennedy Shriver National Institute of Child Health and Human Development, and Judy Levin, Program Officer, Fogarty International Center, National Institutes of Health, for their valuable advice during the preparation of this manuscript.

\section{References}

1. Bhutani VK, Johnson LH, Keren R. Diagnosis and management of hyperbilirubinemia in the term neonate: for a safer first week. Pediatric Clinics of North America, 2004, 51:843-861.

2. Maisels MJ. Epidemiology of neonatal jaundice. In: Maisels MJ, Watchko JF, eds. Neonatal jaundice. Newark, New Jersey, Harwood Academic Publishers, 2000:37-49

3. Ebbesen $\mathrm{F}$ et al. Extreme hyperbilirubinemia in term and near term infants in Denmark. Acta Paediatrica, 2005, 94:59-64.

4. Bhutani VK et al. Kernicterus: epidemiological strategies for its prevention through systems-based approaches. Journal of Perinatology, 2004, 24:650-662.

5. American Academy of Pediatrics Subcommittee on Hyperbilirubinemia. Management of hyperbilirubinemia in the newborn infant 35 or more weeks of gestation. Pediatrics, 2004, 114:297-316.

6. Moerschel SK, Cianciaruso LB, Tracy LR. A practical approach to neonatal jaundice. American Family Physician, 2008, 77:1255-1262.

7. Manning D et al. Prospective surveillance study of severe hyperbilirubinaemia in the newborn in the UK and Ireland. Archives of Disease in Childhood. Fetal and Neonatal Edition, 2007, 92:F342-F346.

8. Allen NM et al. Severe hyperbilirubinaemia and kernicterus: more caution is needed in newborn jaundice surveillance. Irish Medical Journal, 2009, 102:228-229.

9. Burke B et al. Trends in hospitalizations for neonatal jaundice and kernicterus in the United States! 988-2005. Pediatrics, 2009, 123:534-32.

10. Bhutani VK, Johnson L. Kernicterus in the 21st century: frequently asked questions. Journal of Perinatology, 2009, 29(Suppl. 1):S20-S24.

11. Maisels MJ. Neonatal hyperbilirubinemia and kernicterus-not gone but sometimes forgotten. Early Human Development, 2009, 85:727-732.
12. Ogunlesi TA et al. The incidence and outcome of bilirubin encephalopathy in Nigeria: a bi-centre study. Nigerian Journal of Medicine, 2007, 16:354-359.

13. Seoud I et al. Neonatal jaundice in the NICU: an old topic revisited. Journal of Arab Child, 2007, 18:99-108.

14. Seoud I, Abd El-Latif M, Abd El-Latif D. Neonatal jaundice in Cairo University Pediatric Hospital. Journal of Arab Child, 2007, 18:65-72.

15. De Luca D, Carnielli VP, Paolillo P. Neonatal hyperbilirubinemia and early discharge from the maternity ward. European Journal of Pediatrics, 2009, 168:1025-1030.

16. Straczek $\mathrm{H}$ et al. Archives de pédiatrie : organe officiel de la Société française de pédiatrie. [Early discharge of newborns: what problems should we anticipate?]. Archives de Pediatrie, 2008, 15:1076-1082.

17. Moyer VA, Ahn C, Sneed S. Accuracy of clinical judgment in neonatal jaundice. Archives of Pediatrics and Adolescent Medicine, 2000, 154:391-394.

18. Riskin A et al. Is visual assessment of jaundice reliable as a screening tool to detect significant neonatal hyperbilirubinemia? Journal of Pediatrics, 2008, 152:782.e1-787-e2.

19. Rubaltelli FF et al. Transcutaneous bilirubin measurement: a multicenter evaluation of a new device. Pediatrics, 2001, 107:1264-1271.

20. Maisels MJ et al. Evaluation of a new transcutaneous bilirubinometer. Pediatrics, 2004, 113:1628-1635.

21. Kernicterus threatens healthy newborns. Sentinel Event Alert, Issue 18. The Joint Commission [online factsheet] (http://www. jointcommission.org/sentinel_event_alert_issue_18_kernicterus_threatens_healthy_newborns/, accessed 5 May 2012).

22. Atkinson LR et al. Phototherapy use in jaundiced newborns in a large managed care organization: do clinicians adhere to the guideline? Pediatrics, 2003, 111:e555-e561. 